\title{
Özofago-gastrik multiple yabancı cisimlerin komplikasyonsuz olarak endoskopik çıkarılması
}

\section{Endoscopic removal of multiple esophagogastric foreign bodies without complication}

\author{
Süleyman COŞGUN
}

Dumlupınar Üniversitesi Tip Fakültesi Evliya Çelebi Eğitim ve Araştırma Hastanesi Iç Hastalılan, Gastroenteroloji Bölümü, Kütahya

\begin{abstract}
Yabancı cisim yutulması çoğunlukla pediyatrik yaş grubunda görülmekte olup erișkin yaş grubunda sık karşılașılan bir durum değildir. Vakalarda çogunlukla bir veya birkaç adet yabacı cisim vardır. Biz disfaji nedeniyle acile getirilen 17 yaşında şizofren erkek hastada endoskopide özofagus ve midede multiple yabancı cisim saptadık. Ilk çıkarılan cisim endoskopik olarak görünüme göre yapılan tahminden daha uzun ve kalındı.
\end{abstract}

Anahtar kelimeler: Özofagus yabancı cisim, mide yabancı cisim, endoskopik çıkarma

\section{GIIRIS}

Endoskopik girişim gerektiren aciller içerisinde yabancı cisim yutulması gastrointestinal kanamaları takip eder. Çoğunlukla pediatrik yaş grubunda görülen bir durum olmasına rağmen erişkin yaşta görüldügünde daha ciddi morbidite ve mortaliteye sahiptir (1). Erişkin olgularda ağıza alınan iğnenin yanlışlıkla yutulması, iyi çiğnenmeden yutulan et içerisinde kalmış hayvan kemiği takılması gibi durumlara ilaveten psikiyatrik hasta popülasyonunda görülen ve mahkumlarda görülen yabancı cisim yutmaları sayılabilir. Yutulan cismin büyüklüğüne göre birkısmı spontan olarak tahliye edilebilmekle birlikte keskin kenarlılar, piloru geçemeyecek derecede büyük veya uzun olanlar sindirim kanalında takılı kalabilir. Özofagusta impaksiyon; yabancı cisme ait takılma hissi, odinofaji ve disfaji ile prezante olabilirken, midedeki impaksiyonlar epigastik ağrı yapabilir. Biz acil servise disfaji şikayeti ile getirilen 17 yaşındaki şizofren olguyu sunmak istedik.

\section{OLGU SUNUMU}

17 yaşında erkek şizofreni hastası acil polikliniğe, bakım evi yetkililerince, yeni başlayan disfaji ile getirildi. Daha önceden aynı hastanın çocuk cerrahi kliniği tarafından meyve bıçă̆ı dahil multiple yabancı cisim çıkarılma öyküsü vardı. Direkt grafide radyoopak bir cisim görüntüsü alınmamasına rağmen acil endoskopiye alındı. Özofagus lümeninde endoskopun distale geçişine engel olan, lümeni dolduran, uzunluğu tahmin edilemeyen plastik bir cisim izlendi. Yabancı cisim forsepsi ile tutulduğunda ileri gitmiyor ağıza doğru çekilebili-
Foreign body ingestion is more common in children than in adults. Cases present with one or a few objects in the digestive tract. We detected multiple foreign bodies in the esophagus and stomach of a 17-year-old schizophrenic patient by endoscopy. The first foreign body was longer and larger than it appeared when viewed endoscopically.

Key words: Esophageal foreign body, gastric foreign body, endoscopic removal yordu. Boyun geriye ekstansiyona alınarak boğazdan zorlukla ağıza çekildi. Ağızlıktan geçemeyecek derecede büyük olan cisim ağızlık çıkarıldıktan sonra el ile ağızdan alındığında 2 $\mathrm{cm}$ genişliğinde $15 \mathrm{~cm}$ uzunluğunda tuvalet kağıdı tutacağı olduğu anlaşıldı. Olguya tekrar tekrar girişler yapılarak 8 adet yabancı cisim çıkarıldı. Birinci işlemde tuvalet kağıdı tutacağı, tuvalet fırça sapı, çay kaşığı, çorap, kauçuk materyal ve plastik çubuklar çıkarıldı. Sindirilmemiş gıda artıklarından dolayı ve işlemler uzadığı için olgunun midesinin yabancı cisimlerden tamamen temizlenmesi için ilave iki endoskopi seansına daha gereksinim duyuldu. Ikinci seansta 12 ve üçüncü seanslarda 13 parça yabancı cisimler çıkarıldı. Çıkarılan cisimler arasında diş fırçası, kurşun kalem, elbise askısı parçası, sigara izmariti, pipet, tahta parçaları, tuvalet firça sapı ve tuvalet kağıdı tutacağı gibi nesneler vardı (Resim 1-4).

\section{TARTIŞMA}

Yabancı cisimler sindirim kanalını spontan terkedebileceği gibi, impaksiyon, obstrüksiyon, perforasyon ve fistülizasyona neden olabilirler. Hastalar genellikle çocukluk çağında olmakla birlikte daha nadiren erişkin yaşta görülmektedir. Tanı anamnez ve uygun görüntüleme yöntemleri ile konulduktan sonra çıkarma işlemi spontan pasaja bırakma, endoskopik veya açık cerrahi ile çıkarma şeklinde olabilir. Radyolojik görüntüleme yöntemlerinden düz grafi ile saptama oranı \%88 civarındadır (2). Cam, plastik, kumaş, ahşap cisimler, balık kılçığı ve tavuk kemiği direkt grafide görülemeyebilir. 
Yutulan yabancı cisimlerin \%80-90'ı spontan çıkabilmekte olup, \%10-20 olguda endoskopik çıkarım gerekliyken yalnızca \% l'den az olguda cerrahi çıkarım gerekir (3). Radyoopak olup, kenarı keskin olmayan küçük yabancı cisimler 4-6 günde bir çekilecek direkt grafiler ile girişimsiz takip edilebilir (4). 2 cm'den geniş ve $10 \mathrm{~cm}$ 'den uzun nesneler piloru geçemeyeceği için endoskopik çıkarılma gereklidir (5). Ucu sivri cisimlerin çıkarımı esnasında forseps ile sivri olmayan diğer kısımdan tutulup çıkarmak veya overtube kullanmak perforasyon ihtimalini azaltabilir. Cisim çıarılma esnasında üst özofagus sfinkteri düzeyinde forsepsten kurtulma olasilığına karşın bu bölgeden geçiş esnasında kontraksiyonsuz bir dönem gözetilebilir. Yine de bu bölgede forsepsten kurtulan
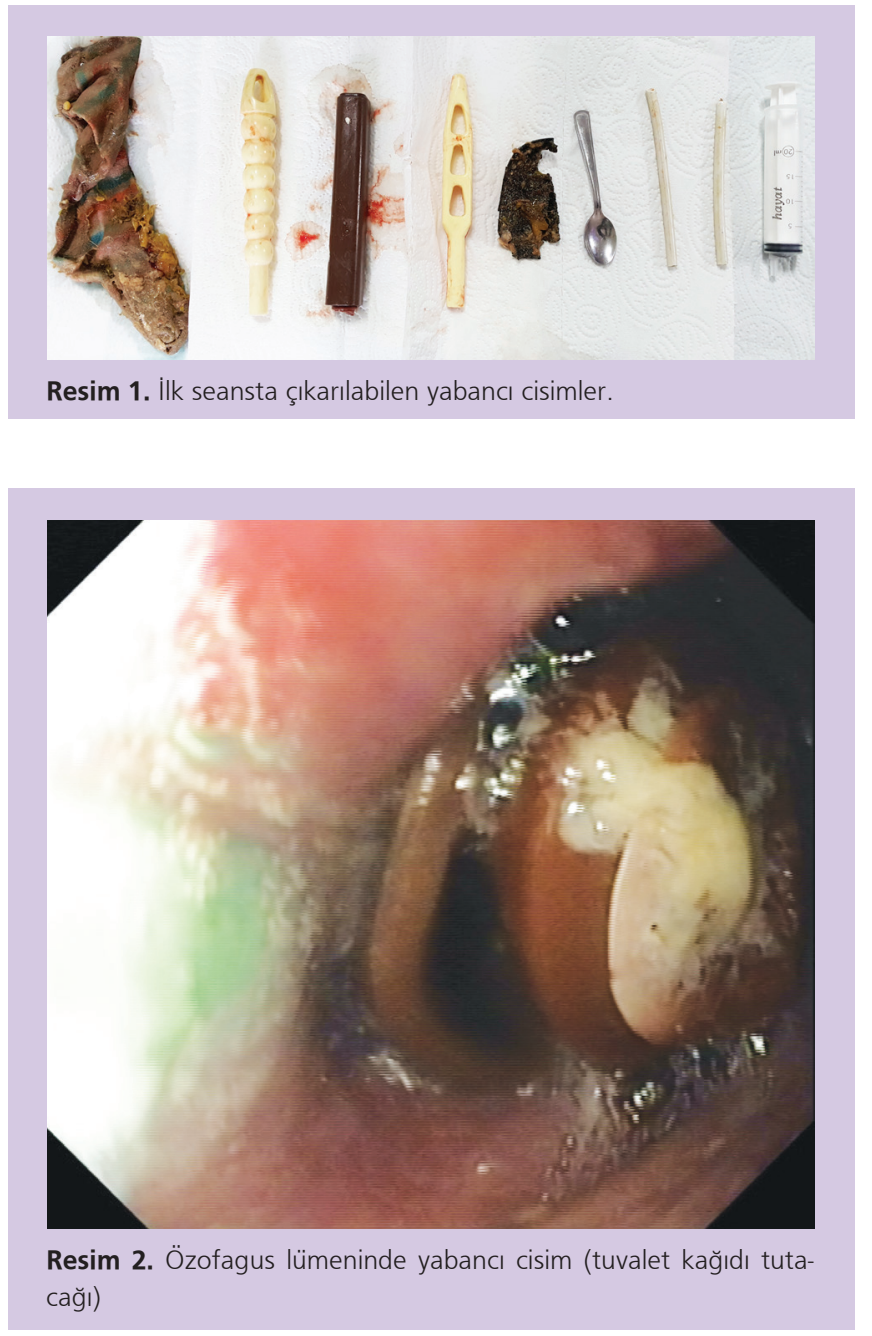

\section{KAYNAKLAR}

1. Eisen GM, Baron TH, Dominitz JA, et al; American Society for Gastrointestinal Endoscopy. Guideline for the management of ingested foreign bodies. Gastrointest Endosc 2002;55:802-6.

2. Weiland ST, Schurr MJ. Conservative management of ingested foreign bodies. J Gastrointest Surg 2002;6:496-500.

3. Webb WA. Management of foreign bodies of the upper gastrointestinal tract: update. Gastrointest Endosc 1995;41:39-51.
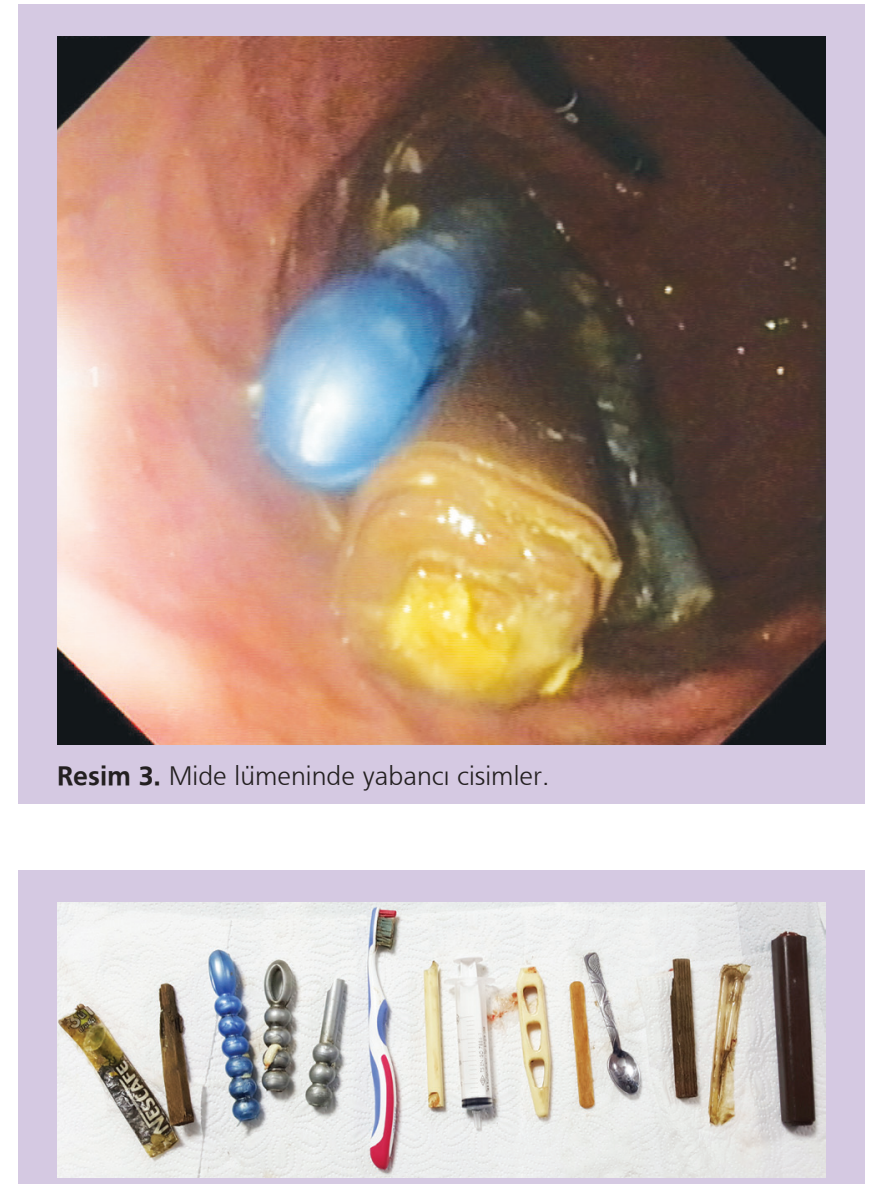

Resim 4. Son seansta çıkarılan yabancı cisimler (ortadaki 20cc'lik enjektör boyut kıyası için konulmuştur)

cisimlerin trakeaya kaçma riski olabilir. Trakeaya komşu bu bölgede kalın cisimlerin forsepsten kurtulması ile trakeaya dış bası yapıp solunum yolunu daraltmaktan endișe edilir. Bizim olgumuzda tuvalet firçası sapı buradan geçişi esnasında forsepsten kurtulmuş ve çıkarılana dek 5-10 dakika kadar trakea ile özofagus ayrımı bölgesinde durmuştur. Ancak trakeanın kartilaj yapısı solunum yolunun kapanmasına engel olmuş ve hastamızda satürasyonda düşme olmamıştır. Böyle bir sorun ile karşılaşılmaması için overtube kullanmak bir alternatif olsa da kalın cisimler standart overtube içine alınamaz.

Sonuç olarak yabancı cisim yutma ile gelen olgularda cerrahi girişime hastayı vermemek için çaba sarfedilmeli ve ne kadar büyük olursa olsun ağız yolu ile giren bir cismin yine ağız yolu ile çıkarılması denenmelidir.

4. Litovitz T, Schmitz BF. Ingestion of cylindrical and button batteries: an analysis of 2382 cases. Pediatrics 1992;89:747-57.

5. Guelfguat M, Kaplinskiy V, Reddy SH, DiPoce J. Clinical guidelines for imaging and reporting foreign bodies. AJR Am J Roentgenol 2014;203:37-53.

6. Ikenberry SO, Jue TL, Anderson MA, et al. Management of ingested foreign bodies and food impactions. Gastrointest Endosc 2011;73:1085-91. 